\title{
The cooperative complex of Argonaute- 2/MicroRNA-146a regulates Hepatitis B Virus replication through FEN1
}

$\min \mathbf{j i}$

North Sichuan Medical University https://orcid.org/0000-0003-3228-0265

\section{Xiaoping Mei}

North Sichuan Medical University

\section{Xunming Jing}

North Sichuan Medical University

\section{$\mathrm{Xu} \mathbf{X u}$}

North Sichuan Medical University

\section{Xing Chen}

North Sichuan Medical University

Wanlong Pan ( $\nabla$ panwl@aliyun.com )

https://orcid.org/0000-0003-4590-0240

\section{Research}

Keywords: HBV, miR-146a, Ago2, FEN1

Posted Date: January 22nd, 2020

DOI: https://doi.org/10.21203/rs.2.21643/v1

License: (9) (i) This work is licensed under a Creative Commons Attribution 4.0 International License. Read Full License 
The cooperative complex of Argonaute-2/MicroRNA-146a regulates Hepatitis B

\title{
Virus replication through FEN1
}

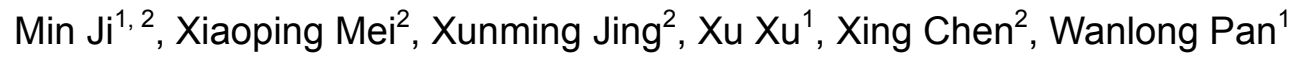 \\ ${ }^{1}$ Department of Microbiology and Immunology\& Experimental Teaching Center for \\ Pathogen Biology and Immunology, North Sichuan Medical College, Nanchong, China, \\ 637000; ${ }^{2}$ Department of Infectious Diseases, Affiliated Hospital of North Sichuan \\ Medical College, Nanchong, China, 637100
}

\begin{abstract}
:
Background: The regulatory of HBV replication is still unclear. FEN1 can repair HBV rcDNA to HBV cccDNA and promote HBV DNA replication. However, its specific regulatory detail remains unclear. MicroRNA regulates gene expression at post-transcriptional level. Especially, miR-146a, it plays an important role that is closely related to regulation of HBV replication. Based on above, we hypothesize that miR-146a may be regulate HBV cccDNA formation through FEN1. So, we will investigate the effect of miR-146a on the replication of hepatitis $B$ virus and its molecular mechanism.
\end{abstract}

Results: We found that level of miR-146a was significantly up-regulated in HepG2.2.15 cells $(11.755 \pm 0.069)$ than that in HepG2 $(1.000 \pm 0.038) \quad(P<0.05)$. Furthermore, HBV-DNA copies and FEN1 were significantly increased and decreased, respectively, in HepG2.2.15 cells transfected with miR-146a mimic and inhibitor for $48 \mathrm{~h},[(3.215 \pm 0.001) ;(2.623 \pm 0.083)]$ compared with the control group $(2.813 \pm 0.015)$ $(P<0.05)$,. After transfection FEN1 plasmid, HBV-DNA Copies $(5.712 \pm 0.371)$ is 
significantly higher than the control group $(2.661 \pm 0.009)(P<0.05)$, and the level of miR-146a (3.431 \pm 0.004$)$ is significantly higher than the control group $(1.023 \pm 0.224)$ $(P<0.05)$. The expression level of IRAK1/TRAF6 are significantly lower and higher $[(0.114 \pm 0.013) ;(0.390 \pm 0.014) ;(1.222 \pm 0.073) ;(2.145 \pm 0.271)]$ than the control group [(1.000 \pm 0.038$) ; \quad(1.007 \pm 0.119)](P<0.05)$ after transfection miR-146a mimic and inhibitor into HepG2.2.15. After Ago2 siRNA, the level of miR-146a $(0.105 \pm 0.002)$ is significantly decreased than the control group $(1.000 \pm 0.041)(P<0.05)$ from Ago2 protein RIP. After transfection Ago2 siRNA then added into exogenous miR-146a into HepG2.2.15, The expression level of FEN1 is significantly reduced $(0.485 \pm 0.100)$ than the control group $(1.000 \pm 0.023)(P<0.05)$, and the HBV-DNA copies is significantly lower $(3.230 \pm 0.047)$ than the control group $(3.789 \pm 0.041)(P<0.05)$.

Conclusion: Ago2 cooperates with miR-146a to regulate the transcription the expression level of FEN1 protein through the downstream target gene IRAK1/TRAF6, then promoting HBV replication.

Keywords: HBV; miR-146a; Ago2; FEN1

\section{Background}

Hepatitis B virus (HBV), a member of the Hepadnaviridae family, a small, partially double-stranded and enveloped DNA virus, is a major cause for a variety of liver diseases, such as chronic hepatitis $B(\mathrm{CHB})$, liver cirrhosis, and hepatocellular carcinoma $(\mathrm{HCC})[1,2]$. According to the latest data published by the $\mathrm{WHO}$, there are about 257 million people infected with HBV worldwide. In 2015, hepatitis B virus resulted in an estimated 887000 deaths, mostly from cirrhosis and hepatocellular 
carcinoma [3, 4]. However, the regulatory of HBV replication is still unclear. In its replication cycle, Infectious HBV particles contain relaxed circular DNA (rcDNA) encapsidated by core proteins[5],After entering the host hepatocyte, rcDNA is repaired into covalently closed circular DNA (cccDNA)[5-8], during HBV infection, ccc DNA acts as a template for the transcription of pgRNA, then reverse transcript viral DNA. HBV DNA will not go away until HBV cccDNA is cleared. It is critical for cure HBV infections. [6, 9]. Unfortunately, we know few on the regulatory mechanism of the transform from rc to ccc.

Interestingly, FEN1 is a structurally specific metal nuclease. It has a spacer-dependent endonuclease activity, and shears the hairpin structure (ie, the pseudo "Y" structure). HBV rcDNA has similar hairpin structure of 9nt redundant sequence at both ends of DNA negative chain. Our previous studies have shown that FEN1 can repair HBV rcDNA to HBV cccDNA and promote HBV DNA replication [10]. However, its specific regulatory detail remains unclear.

MicroRNA is a highly conserved, endogenous non-coding RNA of $20-25$ nt in length, and regulate gene expression at post-transcriptional level $[11,12]$. Currently, some studies provided that microRNAs have a trend of antagonizing HBV protein effects in the regulation of apoptosis, cell cycle and humoral immunity [13]. Especially, miR-146a, it plays an important role that is closely related to inflammation, innate immune and regulation of HBV replication [14, 15]. Based on above, we hypothesize that miR-146a may be regulate HBV cccDNA formation through FEN1. That is to say FEN1 is a target of miR-146a, and then enhance HBV DNA replication. To test this 
hypothesis, we detect the level of FEN1 and HBV DNA copies by overexpressing and interfering with miR-146a, and research the specific molecular mechanism which rcDNA is converted to cccDNA in HBV replication.

In addition, some studies have shown that Ago2 can act as a carrier to play a role in miR-18a interaction [16], which is different from the traditional function that is Ago protein family (Ago1-4) and microRNAs can form immune complexes to promote the processing and maturation of microRNAs [17-19]. Therefore, we hypothesize that Ago2 also plays a very important auxiliary role in the regulation of miR-146a. To verify this hypothesis, we intend to analyze its specific functional mechanisms through Ago2 siRNA and Ago2 RIP.

\section{Results}

miR-146a expression in HBV stable replication cell line HepG2.2.15 is increased

To verify the role of miR-146a in HBV replication, the level of miR-146a was detected in HBV stable cell line HepG2.2.15 and parental cell HepG2 by qRT-PCR. The result was shown the level of miR-146a was significantly increased in HepG2.2.15 (11.755 \pm 0.069$)$, compared with HepG2 group (1.000 \pm 0.038$)$ and the increase is 11 times $(P<0.05)$ (figure.1), suggesting the level of miR-146a may be closely associated with HBV replication. 


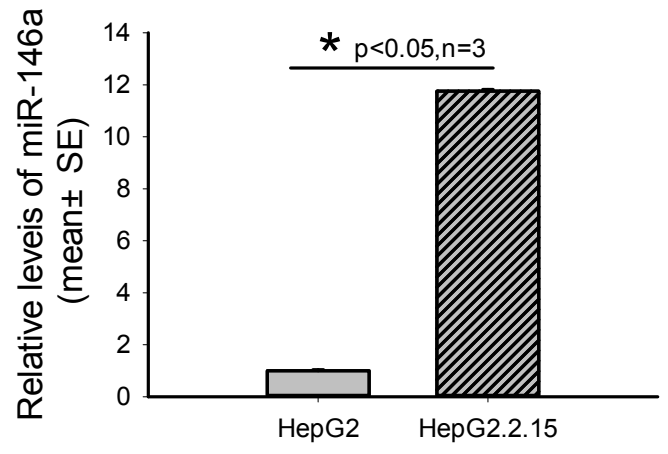

Figure 1 The level of miR-146a in HepG2.2.15 and HepG2 cells

Figure 1 miR-146a expression in HBV stable replication cell line HepG2.2.15 is increased. Expression level of miR-146a in HepG2 and HepG2.2.15 cells was estimated by qRT-PCR from cell lysis supernatant. All experiments were repeated three times. ${ }^{*} P<0.05$.

\section{miR-146a promotes HBV replication and expression}

After transfection of miR-146a mimic and miR-146a inhibitor into HepG2.2.15 cells, the relative level of miR-146a were $(1.487 \pm 0.243)$ and $(0.019 \pm 0.004)$, respectively, it is increased and decreased compared with the control group $(1.001 \pm 0.047)$. The difference is statistically significant $(P<0.05)$ (figure. 2-1). After transfection of miR-146a mimic and miR-146a inhibitor into HepG2.2.15 cells, HBV-DNA copies are $(3.215 \pm 0.001)$ and $(2.623 \pm 0.083)$, respectively, it is increased and decreased than the control group $(2.813 \pm 0.015) \quad(P<0.05)$ (figure. $2-2)$. These results suggest that miR-146a can promote HBV replication. 


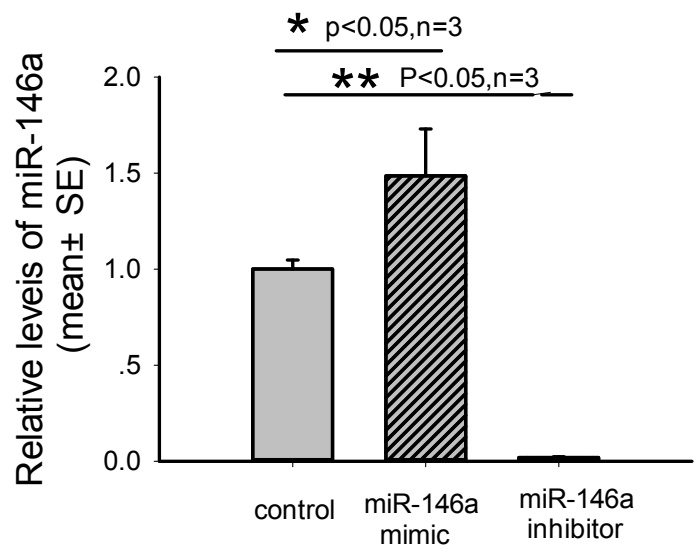

Figure 2-1 The level of miR-146a in HepG2.2.15 after transfection miR-146a

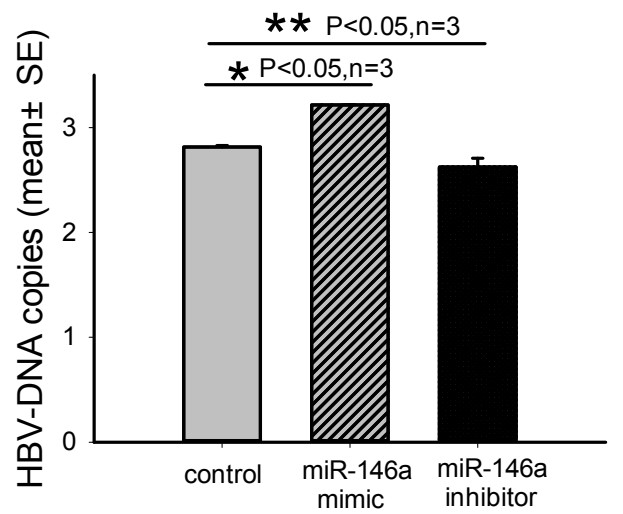

Figure 2-2 The copies number of HBV-DNA in HepG2.2.15 after transfection miR-146a

Figure 2 miR-146a promotes HBV replication and expression. (Figure 2-1)Expression level of miR-146a was analyzed by qRT-PCR in HepG2.2.15 from culture lysis supernatant.( Figure 2-2) HBV DNA copies were analyzed by qRT-PCR in HepG2.2.15 from culture lysis supernatant All experiments were repeated three times. ${ }^{*} \mathrm{P}<0.05$ 
The expression of FEN1 was detected after transfection of miR-146a mimic and inhibitor into HepG2.2.15 cells by qRT-PCR and Western blot. The relative expression of FEN1 was $(1.678 \pm 0.131)$ and $(0.344 \pm 0.045)$, compared with the control group $(1.017 \pm 0.194)$, it was significantly increased and reduced, respectively $(P<0.05)$ (figure. 3-1). After exogenous transfer into FEN1 plasmid, the relative expression of miR-146a was $(5.712 \pm 0.371)$, which was higher than the control group $(1.023 \pm 0.224)$ $(P<0.05)$, HBV-DNA copies was $(3.431 \pm 0.004)$, which was higher than the control group $(2.661 \pm 0.009)(P<0.05)($ Figure 3-2). These data suggesting that miR-146a can promote FEN1 translation, meanwhile FEN1 also promotes the level of miR-146a and HBV-DNA replication.

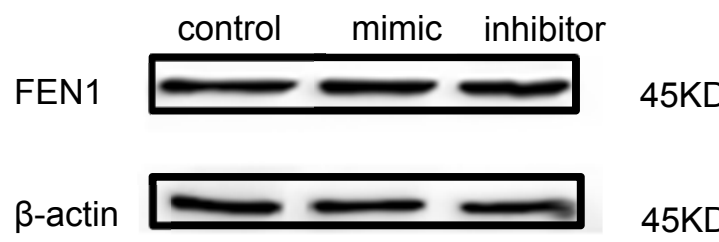

control: HepG2.2.15

mimic: miR-146a mimic inhibitor:miR-146a inhibitor
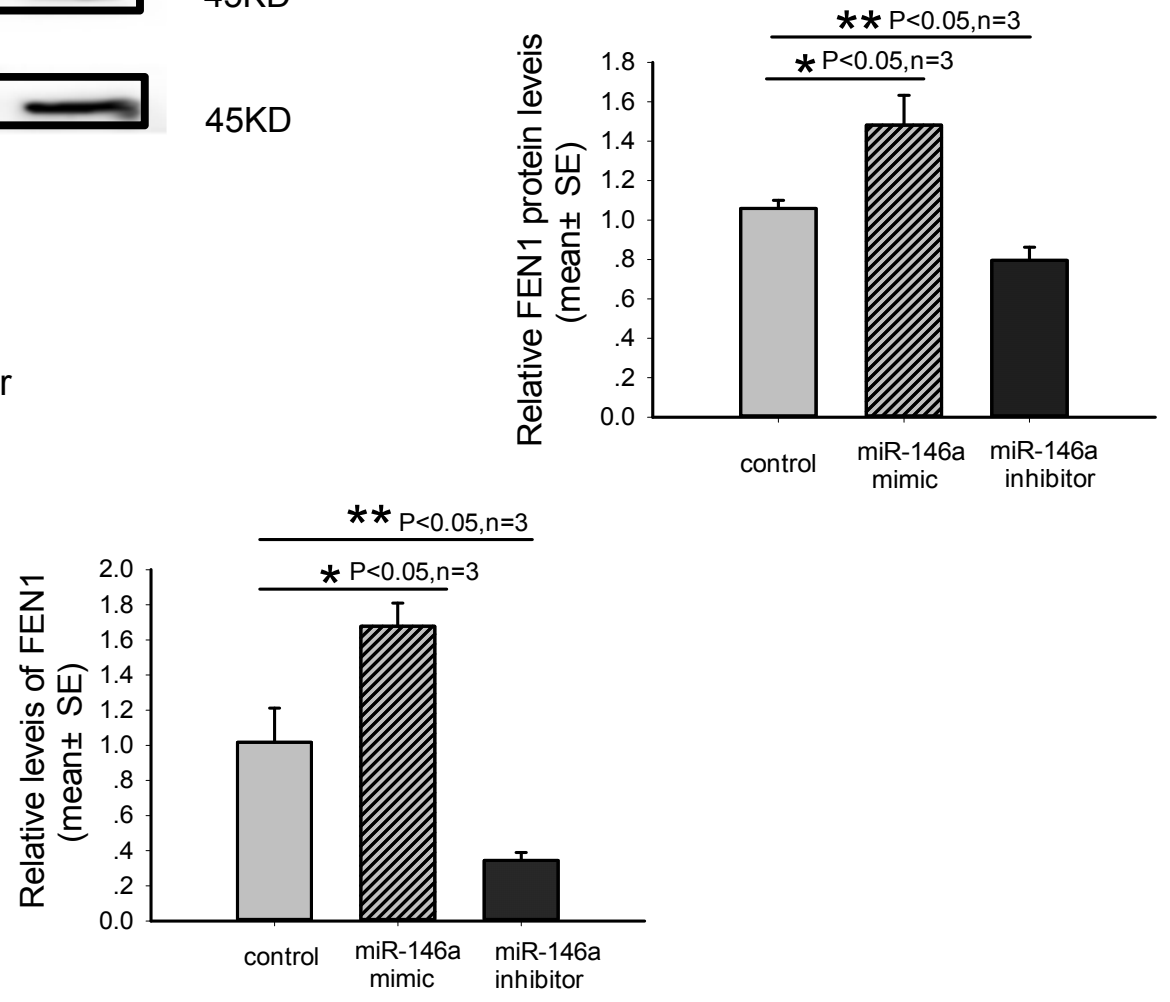

Figure 3-1 The expression of FEN1 in HepG2.2.15 cells after transfection miR-146a by qPCR and western blot 

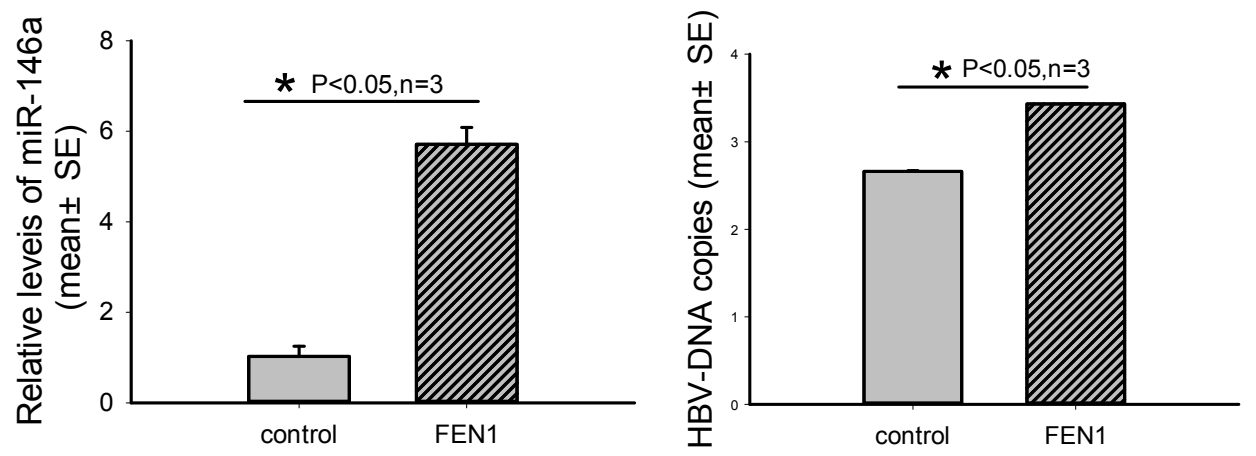

Figure 3-2 The level of miR-146a and HBV DNA copies in HepG2.2.15 cells afrer transfection FEN1

Figure 3 miR-146a promotes FEN1 expression and FEN1 also promotes miR-146a/HBV DNA expression. (Figure 3-1) Expression level of FEN1 was analyzed by qRT-PCR and Western blot in HepG2.2.15 from culture lysis supernatant. (Figure 3-2) Expression level of miR-146a/HBV DNA copies were analyzed by qRT-PCR in HepG2.2.15 from culture lysis supernatant. All experiments were repeated three times. ${ }^{*} \mathrm{P}<0.05$.

\section{miR-146a inhibits the expression of target gene IRAK1/TRAF6}

The bioinformatics software (Target Scan) analyzes to find that IRAK1/TRAF6 is a potential downstream target gene through NF-KB pathway. After transfection with miR-146a mimic into HepG2.2.15 cells and detecting the relative expression level of downstream target genes IRAK1 and TRAF6 by qRT-PCR. Compared with control group (1.000 \pm 0.038$)$ and $(1.007 \pm 0.119)$, the expression of IRAK1 and TRAF6 are decreased, $(0.114 \pm 0.013)$ and $(0.390 \pm 0.014)$, the difference is statistically significant 
$(P<0.05)$; after transfection miR-146a inhibitor into HepG2.2.15 cells, The relative expression level of IRAK1/TRAF6 are higher, $(1.222 \pm 0.073)$ and $(2.145 \pm 0.271)$ than the control group, $(1.000 \pm 0.038)$ and $(1.007 \pm 0.119)(P<0.05)$ (figure 4). The results suggest that miR-146a regulates the expression of FEN1 after inhibiting downstream target genes IRAK1 and TRAF6, and then regulating HBV replication.
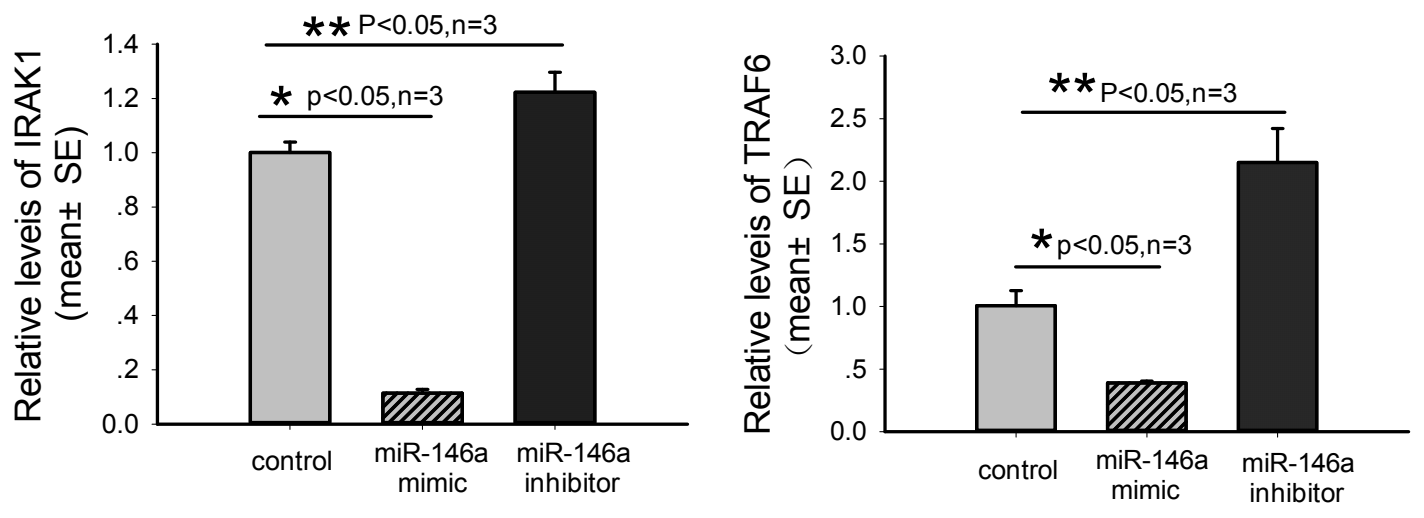

Figure 4 The expression of IRAK1/TRAF6 in HepG2.2.15 cells after transfection $\operatorname{miR}-146 a$

Figure 4 miR-146a inhibits the expression of target gene IRAK1/TRAF6. Expression levels of IRAK1/TRAF6 were analyzed by qRT-PCR in HepG2.2.15 from culture lysis supernatant. All experiments were repeated three times. ${ }^{*} \mathrm{P}<0.05$.

\section{Ago2 mediates miR-146 regulated HBV replication}

After transfection Ago2 siRNA and miR-146a respectively into HepG2.2.15 cells, the expression of Ago2 protein was detected by qRT-PCR and western blot. The

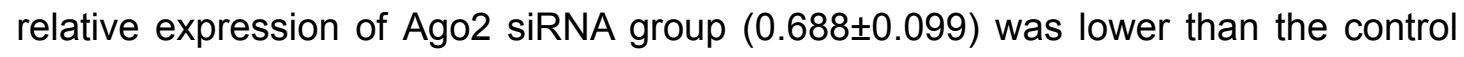
group (1.002 \pm 0.069$)$. The difference was statistically significant $(P<0.05)$, the expression of Ago2 is increased when we add miR-146a (Figure 5-1), indicating the expression of Ago2 protein was silenced by Ago2 siRNA. 

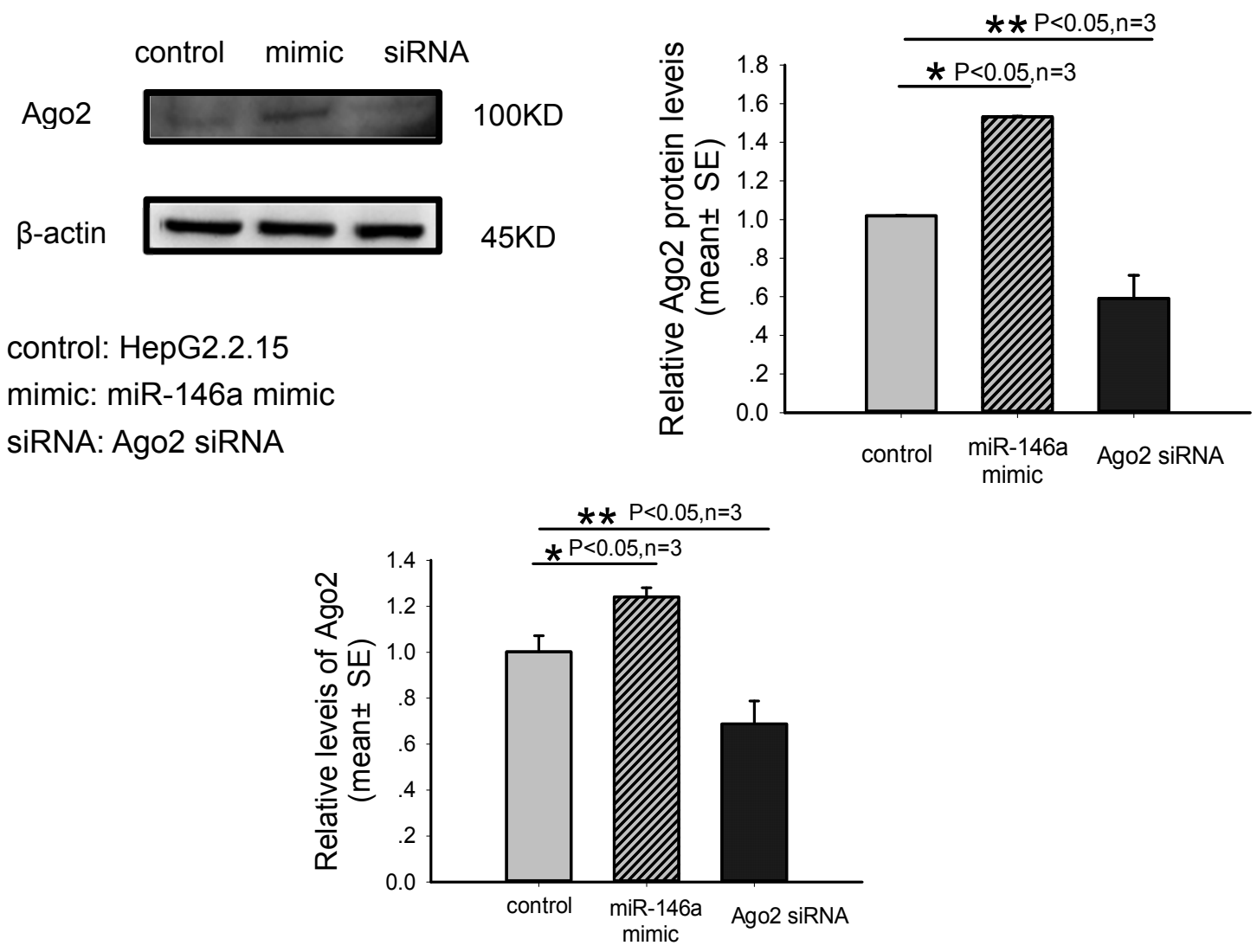

Figure 5-1 The expression of Ago2 in HepG2.2.15 cells after transfection miR-146a and Ago2 siRNA

After Ago2 RIP, the level of miR-146a was detected by qRT-PCR. The relative level of miR-146a in Ago2 siRNA group (0.105 \pm 0.002$)$ was lower than the control group (1.000 \pm 0.041$)$, the difference is statistically significant $(P<0.05)$ (Figure 5-2).

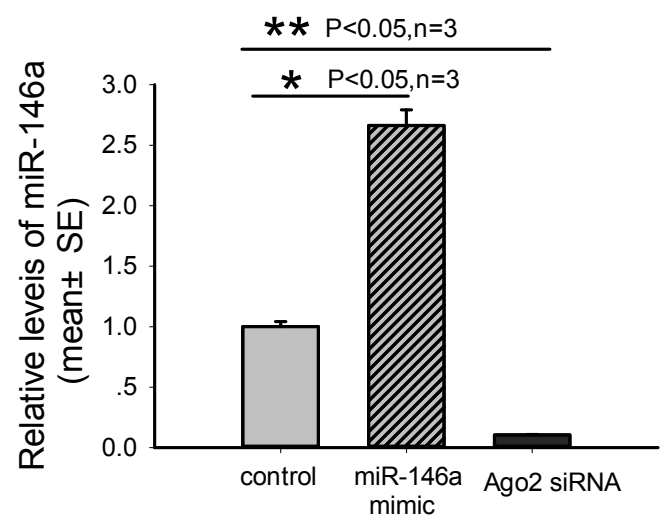


Figure 5-2 The level of miR-146a after transfection miR-146a mimic and Ago2 siRNA into HepG2.2.15 cells

Transfection miR-146a mimic after Ago2 siRNA, the expression of FEN1 and HBV DNA copies were reduced

Ago2 siRNA was transfected into HepG2.2.15 cells for 24 hours, following treated by exogenous addition of miR-146a for 24 hours, detecting the expression of FEN1 and HBV DNA copies by qRT-PCR. The relative expression level of FEN1 in Ago2 siRNA group $(0.485 \pm 0.100)$ was significantly reduced, compared with the control group (1.000 \pm 0.023$)$, the difference is statistically significant $(P<0.05)$ (Figure 5-3), and the HBV DNA copies $(3.230 \pm 0.047)$ is also significantly reduced than the control group $(3.789 \pm 0.041)(P<0.05)($ Figure 5-4). The results indicate that the mature miR-146a does not work if have no Ago2 protein. Ago2 act as a carrier with miR-146a to play a regulatory role.

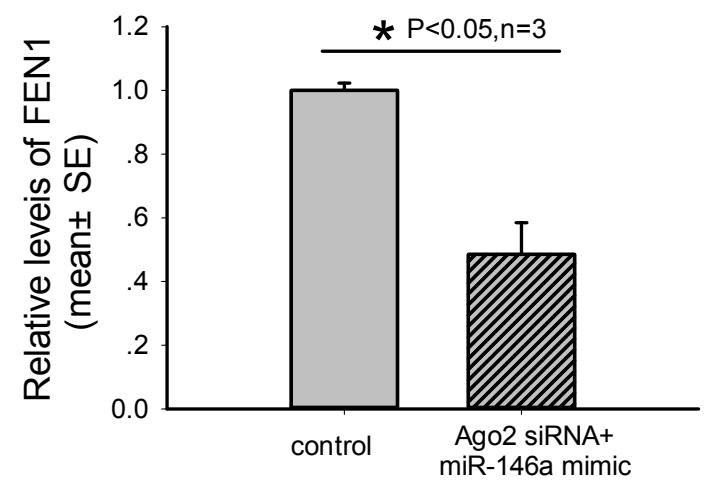

Figure5-3 The expression of FEN1 after transfection Ago2 siRNA and miR-146a into HepG2.2.15 


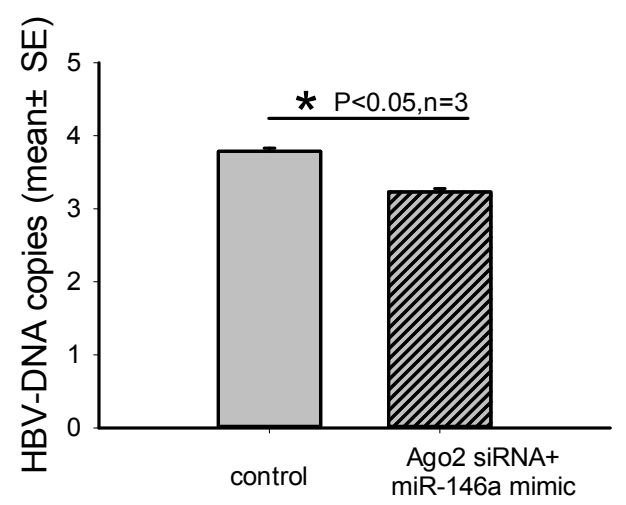

Figure5-4 The copies of HBV DNA after transfection Ago2 siRNA and miR-146a into HepG2.2.15

Figure 5 Ago2 mediates miR-146 regulated HBV replication. (Figure 5-1) Expression level of Ago2 were analyzed by qRT-PCR and Western blot in HepG2.2.15 from culture lysis supernatant. (Figure 5-2) Expression level of miR-146a was analyzed by qRT-PCR in HepG2.2.15 from culture lysis supernatant. (Figure5-3) Expression level of miR-146a was analyzed by qRT-PCR in HepG2.2.15 from culture lysis supernatant. (Figure5-4) HBV DNA copies were analyzed by qRT-PCR in HepG2.2.15 from culture Iysis supernatant. All experiments were repeated three times. ${ }^{*} \mathrm{P}<0.05$.

\section{Discussion}

We found that miR-146a is significantly elevated in the HepG2.2.15 cell line by detecting the expression level of miR-146a in the HepG2 and the HBV stable replication cell line HepG2.2.15. It is suggest that miR-146a seems to regulate and promote HBV DNA expression and replication. Based on above, we detected the expression of FEN1 and HBV DNA copies by qRT-PCR after overexpressing and interfering with miR-146a into HepG2.2.15 cell line, showing that HBV DNA copies 
number and the expression level of FEN1 in miR-146a mimic group were obvious increaesed, which is consistent with the results of wang [1]et al, suggest that miR-146a promote HBV replication and enhance the expression of FEN1. Related studies have revealed a partial immune mechanism by which miR-146a affects HBV DNA replication $[20,21]$. For example, during hepatitis $B$ virus infection, miR-146a causes T lymphocyte function impaired and can target levels of RIG- I /RIG-G the innate immune response impaired in the cell and promote HBV replication. However, it lacks an explanation of the molecular mechanism of HBV replication. Interestingly, our previous study found that FEN1 is a key enzyme in the regulation of HBV DNA replication, and while miR-146a enhances HBV DNA replication, FEN1 levels also increased, indicating that miR-146a is most likely affects HBV DNA replication by regulating the key enzyme of FEN1. In the present study, we demonstrated that miR-146a promoted HBV replication and expression by targeting FEN1.

FEN1 is a structurally specific metal nuclease that exists in mitochondria and nucleus [22]. FEN1 has multiple functions, including promoting DNA maturation, replication and regulating protein metabolism [23]. FEN1 promotes replication of HBV DNA that the reason may be the HBV rcDNA to HBV cccDNA structural repair and transformation stage. The HBV rcDNA negative strand is a DNA structure that is not closed and contains redundant sequences at the $5^{\prime}$ and $3^{\prime}$ ends. This hairpin structure must be repaired in order to replicate successfully. In the process of forming cccDNA, due to the special structure of the negative strand of HBV rCDNA, FEN1 exerts a spacer-dependent endonuclease activity, shears the hairpin structure (ie, the pseudo 
"Y" structure) and the formation of a complete closed loop structure under the action of polymerase and ligase, thereby promoting the replication of viral DNA. In addition, for the RNA primer of the 5'-end of the positive strand of HBV rcDNA, FEN1 can also excise the RNA primer by its 5'-3'flap endonuclease activity, and then extend and close to form a complete cccDNA molecule $[8,10]$. Therefore, we transferred the exogenous FEN1 plasmid into the HepG2.2.15 cell line and observed the level of miR-146a and HBV DNA copies, which were found to be significantly higher than the control group, indicating that FEN1 can increase miR-146a and promote HBV DNA replication. At the same time, overexpression and interference with miR-146a, observed the expression level of FEN1, found that miR-146a overexpression group and interference group were significantly higher and lower than the control group, suggesting that miR-146a and FEN1 have mutual regulation. The reasonable explanation is during HBV infection, miR-146a expression is up-regulated, and the expression of cccDNA is indirectly promoted by enhancing FEN1 expression, then enhancing HBV DNA replication. Meanwhile, miR-146a may provide a more suitable environment for FEN1 to exert endonuclease activity. The host environment enables it to regulate HBV replication more effectively. That is to say FEN1 and miR-146a form a positive feedback regulation mechanism, When the level of miR-146a was increased, the expression of FEN1 was promoted, at the same time FEN1 also promotes the level of miR-146a in turn. FEN1 and miR-146a promote expression to each other. Following, we used bioinformatics software analysis to find that IRAK1/TRAF6 is a potential downstream target gene of miR-146a[24], and qRT-PCR results show that 
the relative expression level of IRAK1/TRAF6 after miR-146a mimic and inhibitor into HepG2.2.15 cell. Compared with the control group, it was significantly reduced or increased, that is, miR-146a promoted the replication of HBV DNA by inhibiting the expression of the downstream target gene IRAK1/TRAF6. The possible reason is that there are multiple nuclear factor-kappaB (NF-kB) binding sites in the promoter region of miR-146a gene, and miR-146a can target the interfering molecule interleukinbetween NF-KB. 1 receptor-associated kinase-1 (IRAK1) and tumor necrosis factor receptor-associated factor-6 (TRAF6), thereby reducing NF-KB activity and preventing the occurrence of hyperimmune inflammatory response[24, 25], and some research and analysis show that FEN1 is significantly enriched in the NF-KB pathway, that is, its expression level is elevated, which fully indicates that miR-146a elevate the expression of FEN1 after inhibiting downstream target genes, and then regulating HBV replication.[26]

In addition, other studies have shown that Ago2 can act as a carrier to play a role in miR-18a interaction[16], which is different from the traditional function that is Ago protein family (Ago1-4) and microRNAs can form immune complexes to promote the processing and maturation of microRNAs[17, 18]. Therefore, we hypothesize that Ago2 also plays a very important auxiliary role in the regulation of miR-146a. To verify this hypothesis, we intend to analyze its specific functional mechanism through Ago2 siRNA and Ago2 RIP. We overexpressed miR-146a and transferred Ago2 siRNA into HepG2.2.15 cell. After 48 hours, RIP isolated Ago2 protein, detecting the level of miR-146a by qRT-PCR and found that the level of miR-146a in Ago2 siRNA group 
was significantly decreased compared with control group. It indicates that Ago2 does form a complex with miR-146a. When exogenously elevated miR-146a and interferes with Ago2 protein, the expression level of FEN1 and HBV DNA copies were significantly decreased, which indicates Ago2 act as a carrier with miR-146a to play a regulatory role.

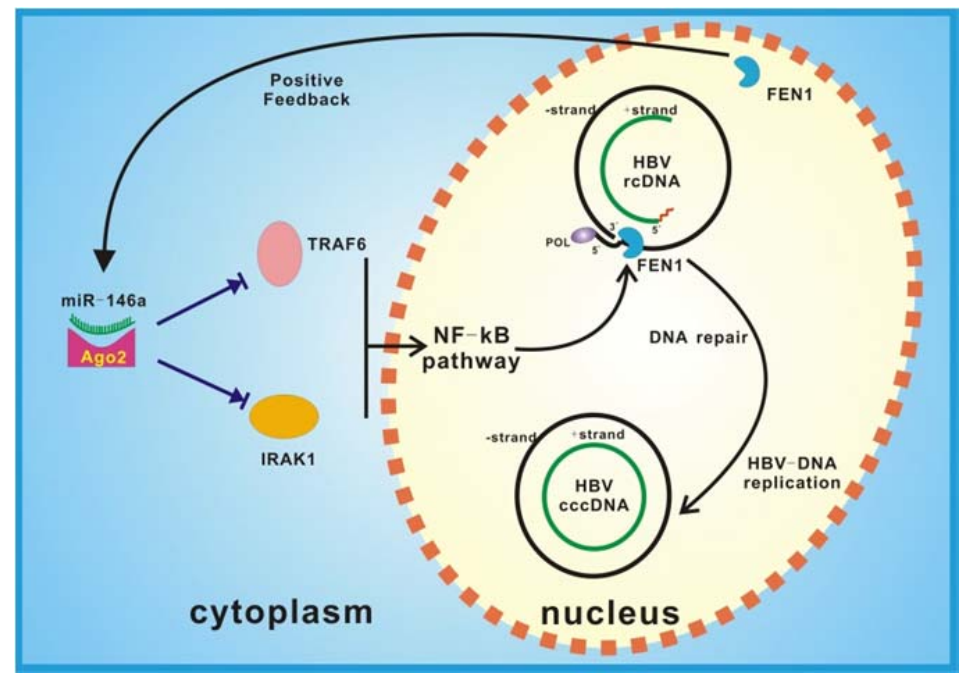

In conclusion, we figured out a new miR-146a $\rightarrow$ FEN1 $\rightarrow$ HBV DNA regulatory axis in HBV infection, which helps to better understand the miRNA-HBV interaction and provide a theoretical basis for the pathogenesis of HBV. Of course, further in vivo experiments were conducted to study the relationship between miR-146a, HBV and FEN1 in order to further deepen the understanding of hepatitis B virus-host interaction and we need more experiments to identify these new potential molecular targets we found for the prevention and treatment of $\mathrm{CHB}[7]$.

\section{Materials and methods}

\section{Cell culture and transfection}

Human HCC cell lines HepG2 and HepG2.2.15 were purchased from Saibo Kang Biotechnology Co (Shanghai, China). All cells were cultured in Dulbecco's modified 
Eagle's medium (DMEM) containing 10\% heat-inactivated fetal bovine serum (FBS), $100 \mathrm{U} / \mathrm{ml}$ penicillin and $100 \mu \mathrm{g} / \mathrm{ml}$ streptomycin at $37^{\circ} \mathrm{C}$ in a $5 \% \mathrm{CO} 2$ incubator. HepG2.2.15, derived from HepG2 cell line, possesses HBV genome and is able to generate HBV particle. G418 (Shanghai yuanye BiO-Technology Co,Ltd) was added into culture medium to maintain stable HBV replication. miR-146a mimic and miR-146a inhibitor obtained from Ribobio INC (Guangzhou, China). FEN1 plasmid was obtained from Pre-build save.[10] Ago2 siRNA were obtained from JTSBIO (wuhan, China), Plasmids and miR-146a mimic or inhibitor were transfected into HepG2.2.15 at the specfied concentrations using Lipofectamine 2000 reagent (Invitrogen, Carlsbad, CA, USA) according to the manufacturer's protocol. Cells were collected for further analysis $48 \mathrm{~h}$ post transfection.

\section{Quantitative real-time PCR for mRNA/microRNA}

Total RNA from cultured cells was isolated using TRIzol reagent (Invitrogen USA). The primers of FEN1, IRAK1/TRAF6, Ago2, HBV DNA and $\beta$-actin were designed and synthesized by Sangon Biotech (Chengdu, China). A total of $2 \mu \mathrm{g}$ RNA was reversely transcribed into the first-strand cDNA with random primers and Revert Aid First Strand cDNA Synthesis Kit (ThermorFisher USA). microRNA was isolated according to the instruction manual of Qiagen miRNeasy Serum/Plasma (QIAGEN,USA). The primers of miR-146a and U6 were designed and synthesized by Utysen bioengineering Co, Ltd (Chengdu), cDNA was performed through QIAGEN miRNeasy Mini KIT (QIAGEN, USA). qRT-PCR reactions were performed by the TaqMan MicroRNA Assays (QIAGEN,USA) and UltraSYBR Mixture (WCBIO, Jiangsu) on the Bio-Rad Sequence 
Detection system (Applied Biosystems, Foster City, CA, USA), respectively. The reaction conditions of the miR-146a PCR were as follows: 1 cycle at $95^{\circ} \mathrm{C}$ for 10 minutes, followed by 45 cycles at $95^{\circ} \mathrm{C}$ for 10 seconds, $52^{\circ} \mathrm{C}$ for 30 seconds and $60^{\circ} \mathrm{C}$ for 30 seconds. IRAK1/TRAF6, FEN1, Ago2, HBV DNA and $\beta$-actin reaction conditions were as follows: 1 cycle at $95^{\circ} \mathrm{C}$ for 10 minutes, followed by 37 cycles at $95^{\circ} \mathrm{C}$ for 15 seconds and $60^{\circ} \mathrm{C}$ for 30 seconds. The relative expressions level of miR-146a and IRAK1/TRAF6, FEN1 and Ago2 were calculated using the $2-\triangle \triangle \mathrm{Ct}$ method and normalized to U6 and $\beta$-actin, respectively. The copies number of HBV-DNA were calculated using standard curve line, and all the reactions were performed repeat three times. The primer sequences used for PCR were:

\begin{tabular}{ll}
\hline name & Primer sequence $\left(5^{\prime}-3^{\prime}\right)$ \\
\hline miR-146a & F:GAGAACTGAATTCCATGGGT \\
& R:GC-CTACAGCCTCCTAGTACA \\
& P:GAGACCGCAGACCGCAAC \\
F6 & F:GCTTCGGCAGCACATATACT \\
& R:AACGCTTCACGAATTTGCGT \\
P:TGGCCCCTGCGCAAGGATGAC & F:TGCAGATCTACAAGAAGCACCT \\
R:CCTCTCGTACACCTGGGTCATAG & F:AAGGAGAGAATCAGAGCAAGTG \\
\hline TRAF6 & R: GCAGTTCCACCCACACTATCA \\
\hline
\end{tabular}


R:AGGACACCCACTTGATGGACA

Ago2 siRNA

F: GGAUAUGCCUUCAAGCCUCTT

R: GAGGCUUGAAGGCAUAUCCTT

FEN1

F: CAAAGGCCAGTCATCCСTCCT

R: GCGAACAGCAATCAGGAACTG

$\beta$-actin

F:CTCCATCCTGGCCTCGCTGT

R: GCTGTCACCTTCACCGTTCC

HBV DNA

F: ACCGACCTTGAGGCATACTT

R: GC-CTACAGCCTCCTAGTACA

\section{Western blot}

Total proteins from HepG2.2.15 cells were isolated with RIPA reagents (Beyotime Biotechnology Shanghai). Equivalent amounts of proteins were subjected to $12 \%$ SDS-PAGE and transferred to PVDF membrane. After being blocked with $5 \%$ nonfat milk for $3 \mathrm{~h}$, the membranes were then incubated overnight with the primary antibody against FEN1(ZEN BIO) and $\beta$-actin (ZEN BIO) at $4^{\circ} \mathrm{C}$ overnight, secondary antibody (ZEN BIO) labeled with horseradish peroxidase (HRP)-linked for $1 \mathrm{~h}$. After washing by TBST, the ECL kit was applied and chemiluminescence was detected by a gel imaging system. The gray value of each specific strip was digitized by ImageJ analysis software.

\section{Extraction of HBV replication intermediates}

After 48 hours of HepG2.2.15 cell transfection, the HBV virus core particle DNA extract was extracted from HBV intermediate, PEG8000 was allowed to incubated on 
ice for 40 minutes, then incubated with digestive juice and proteinase $\mathrm{K}$ were overnight; phenol chloroform extracted DNA, isopropanol ethanol precipitated, buffer dissolved precipitate

\section{RNA-binding protein immunoprecipitation (RIP) assay}

The cells after 48 hours of transfection were collected, and were immunoprecipitated using the Magna RIP kit (\#17-700, Millipore) following the manufacturer's instructions with an anti-Ago2 antibody (Millipore, \# 03-110) and control lgG from cell lysis supernatant, The quantification of miR-146a was carried out on using Bio-Rad Sequence Detection system the TaqMan MicroRNA Assays (Qiagen, Chatsworth,CA)

\section{Statistical analysis}

All data were presented as mean \pm standard error (SE) from at least three independent experiments and analyzed by Microsoft Excel software. For analysis of differences between two or more groups, Student's $t$ test or one-way analysis of variance was applied. $\mathrm{P}$ value $<0.05$ was considered to be statistically significant.

\section{Abbreviations:}

HBV, Hepatitis B virus; FEN1, Flap endonuclease 1; IRAK1 Interleukin-1 receptor-associated kinase 1;TRAF6,TNF Receptor Associated Factor6; miRNA, microRNA; Ago2, Argonaute 2; RIP, RNA Binding Protein Immunoprecipitation; rcDNA, relaxed circular DNA; cccDNA, covalently closed circular DNA.

\section{Acknowledgements:}

Thanks to Innovation Platform for Basic Medical Research of North Sichuan Medical 
College

\section{Authors' contributions}

Co-first author: Xiaoping Mei: data analysis, to look for downstream target genes by bioinformatics software analysis. E-mail: myhlillian@163.com. Xunming Jing: designed the primer and some experiment methods: E-mail: 1124377569@qq.com The second author: Xu Xu: culture HepG2 and HepG2.2.15 cells. E-mail: 562889659@qq.com The third author: Xing Chen: some preparation work for WB and transfection. E-mail: 505647754@qq.com

\section{Funding}

This study was supported by the cooperation project between Nanchong with NSMC (grant No.18SXHZ0272); Key Projects of Sichuan Provincial Education Department (grant No.13ZA0221); 2019 National Pre-Research Project of NSMC; Sichuan Provincial Health Department Project (grant No.130287); North Sichuan Medical College Project (grant No.CBY12-A-ZP01)

\section{Availability of data and materials}

The datasets used and/or analyzed during this study are included in this published article [and its additional file] or are available from the corresponding author on reasonable request.

\section{Ethics approval and consent to participate}

Not applicable.

\section{Consent for publication}

Not applicable. 


\section{Competing interests}

The authors declare that they have no competing interests.

\section{Author details}

Author: Ji Min, Department of Infectious Diseases graduate, Contact: 15881781026, email: 861762921@qq.com

Corresponding author: Pan Wanlong, associate professor, Contact: 13198198108

E-mail: panwl@aliyun.com

\section{References:}

[1] Wang Y, Li Y. miR-146 promotes HBV replication and expression by targeting ZEB2. Biomed Pharmacother. 99 (2018) 576-582.

[2] Li JF,Dai XP,Zhang W, Sun SH, Zeng Y, Zhao GY, Kou ZH, Guo Y, Yu H, Du

LY, Jiang SB, Zhou YS.Upregulation of microRNA-146a by hepatitis B virus X protein contributes to hepatitis development by downregulating complement factor H. MBio. 6 (2015) e02459-14.

[3] Xing T,Zhu J,Xian J,Li A,Wang X,Wang W,Zhang Q. miRNA-548ah promotes the replication and expression of hepatitis B virus by targeting histone deacetylase 4 . Life Sci. 219 (2019) 199-208.

[4] Hu J,Protzer U,Siddiqui A.Revisiting Hepatitis B virus: Challenges of Curative Therapies. Journal of Virology.93 (2019) e01032-19.

[5] Seeger C,Mason WS.Molecular biology of hepatitis B virus infection. Virology.479-480 (2015) 672-86. 
[6] Guo JT, Guo H.Metabolism and function of hepatitis B virus cccDNA: Implications for the development of cccDNA-targeting antiviral therapeutics. Antiviral Res.122 (2015) 91-100.

[7] Levrero M,Pollicino T,Petersen J,Belloni L,Raimondo G,Dandri M.Control of cccDNA function in hepatitis B virus infection. J Hepatol. 51 (2009) 581-92.

[8] Kitamura K, Que L,Shimadu M,Koura M,Ishihara Y,Wakae K,Nakamura T,Watashi K,Wakita T,Muramatsu M. Flap endonuclease 1 is involved in cccDNA formation in the hepatitis B virus. PLOS Pathogens. 14 (2018) e1007124.

[9] Zoulim F,Durantel D. Antiviral therapies and prospects for a cure of chronic hepatitis B.Cold Spring Harb Perspect Med. 5 (2015) a021501.

[10] Pan Wanglong, Fang yan, Xu ge, Shan xuefeng, Xu lei,Chen ke,Huang ailong,Hu jieli.Effect of structure-specific nuclease FEN1 on HBV replication. Journal of the Third Military Medical University.34 (2012)1925-1928.

[11] Liu Y,Zhao JJ,Wang CM,Li MY, Han P,Wang L,Cheng YQ,Zoulim F,Ma X,Xu DP.Altered expression profiles of microRNAs in a stable hepatitis B virus-expressing cell line. Original article.122 (2009)10-14.

[12] Weldon Furr J,Morales-Scheihing D,Manwani B,Lee J,McCullough LD.Cerebral Amyloid Angiopathy, Alzheimer's Disease and MicroRNA: miRNA as Diagnostic Biomarkers and Potential Therapeutic Targets. Neuromolecular Med.2019. doi: 10.1007/s12017-019-08568-0.

[13] Wang G,Dong F,Xu Z,Sharma S, Hu X,Chen D,Zhang L,Zhang J,Dong Q.MicroRNA profile in HBV-induced infection and hepatocellular carcinoma. BMC 
Cancer.17 (2017) 805.

[14]Riazalhosseini B,Mohamed Z,Apalasamy YD,Eng HS,Mohamed R.Association between microRNA-196A2 and microRNA-146A polymorphisms and progression to cirrhosis and hepatocellular carcinoma in patients with viral hepatitis B.

Pharmacogenetics and Genomics.26 (2016) 74-79.

[15] Saba R,Sorensen DL,Booth SA.MicroRNA-146a: A Dominant, Negative Regulator of the Innate Immune Response. Frontiers in Immunology.21 (2014) 578.

[16] Ferreira R,Santos T,Amar A, Gong A,Chen TC ,Tahara SM, Giannotta SL, Hofman FM.Argonaute-2 promotes miR-18a entry in human brain endothelial cells. J Am Heart Assoc.3 (2014) e000968.

[17] Bellissimo T,Tito C,Ganci F,Sacconi A,Masciarelli S,Di Martino G,Porta N,Cirenza M,Sorci M,De Angelis L,Rosa P,Calogero A,Fatica A,Petrozza V,Fontemaggi

G,Blandino G,Fazi F.Argonaute 2 drives miR-145-5p-dependent gene expression program in breast cancer cells. Cell Death \& Disease.10 (2019) 17.

[18] Choe J,Cho H,Lee HC,Kim YK.microRNA/Argonaute 2 regulates nonsense-mediated messenger RNA decay. EMBO Rep.11 (2010) 380-6.

[19] Winter J,Diederichs S.Argonaute proteins regulate microRNA stability: Increased microRNA abundance by Argonaute proteins is due to microRNA stabilization.RNA Biology.8 (2011) 1149-1157.

[20] Wang S,Zhang X,Ju Y,Zhao B,Yan X,Hu J,Shi L,Yang L,Ma Z,Chen L,Liu Y,Duan Z,Chen X,Meng S.MicroRNA-146a Feedback Suppresses T Cell Immune Function by Targeting Stat1 in Patients with Chronic Hepatitis B. The Journal of Immunology.191 
(2013) 293-301.

[21] Hou Z, Zhang J,Han Q,Su C,Qu J, Xu D, Zhang C,Tian Z.Hepatitis B virus inhibits intrinsic RIG-I and RIG-G immune signaling via inducing miR146a.Sci Rep.6 (2016) 26150.

[22] Liu P, Qian L, Sung JS, de Souza-Pinto NC, Zheng L, Bogenhagen DF, Bohr VA, Wilson DM 3rd, Shen B, Demple B.Removal of Oxidative DNA Damage via FEN1-Dependent Long-Patch Base Excision Repair in Human Cell Mitochondria. Molecular and Cellular Biology.28 (2008) 4975-4987.

[23] Zheng L,Jia J,Finger LD,Guo Z,Zer C,Shen B.Functional regulation of FEN1 nuclease and its link to cancer. Nucleic Acids Research.39 (2011) 781-794.

[24] Bhaumik D,Scott GK,Schokrpur S,Patil CK,Campisi J,Benz CC.Expression of microRNA-146 suppresses NF-jB activity with reduction of metastatic potential in breast cancer cells. Oncogene.27 (2008) 5643-7.

[25] Wu H,Fan H,Shou Z,Xu M,Chen Q,Ai C,Dong Y, Liu Y, Nan Z,Wang Y,Yu T,Liu $X$.Extracellular vesicles containing miR-146a attenuate experimental colitis by targeting TRAF6 and IRAK1. International Immunopharmacology.68 (2019) 204-212. [26] Gao X, Wang J, Zhang S.Integrated Bioinformatics Analysis of Hub Genes and Pathways in Anaplastic Thyroid Carcinomas. International Journal of Endocrinology.2019 (2019) 9651380. 
Figures

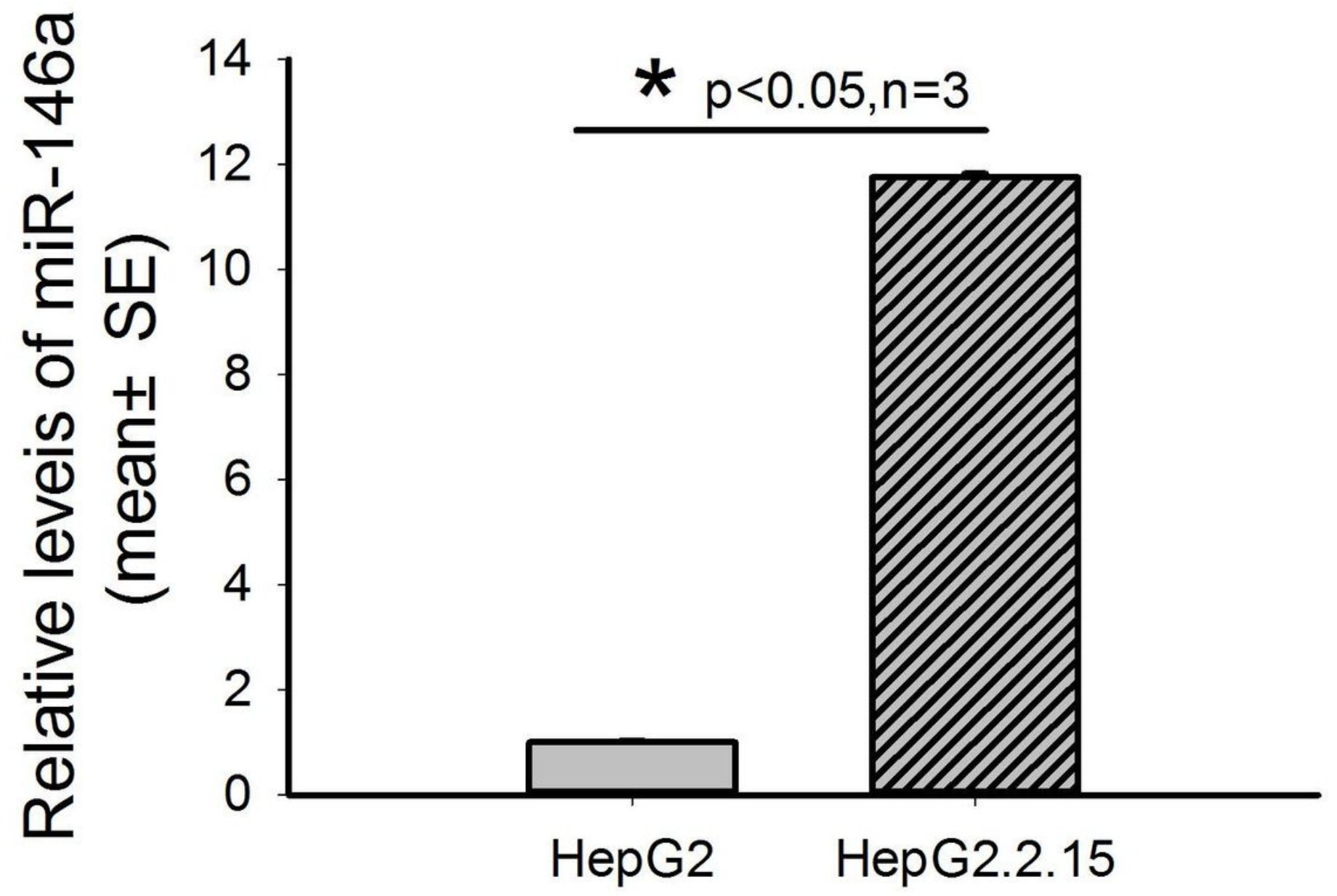

Figure 2

The level of miR-146a in HepG2.2.15 and HepG2 cells 


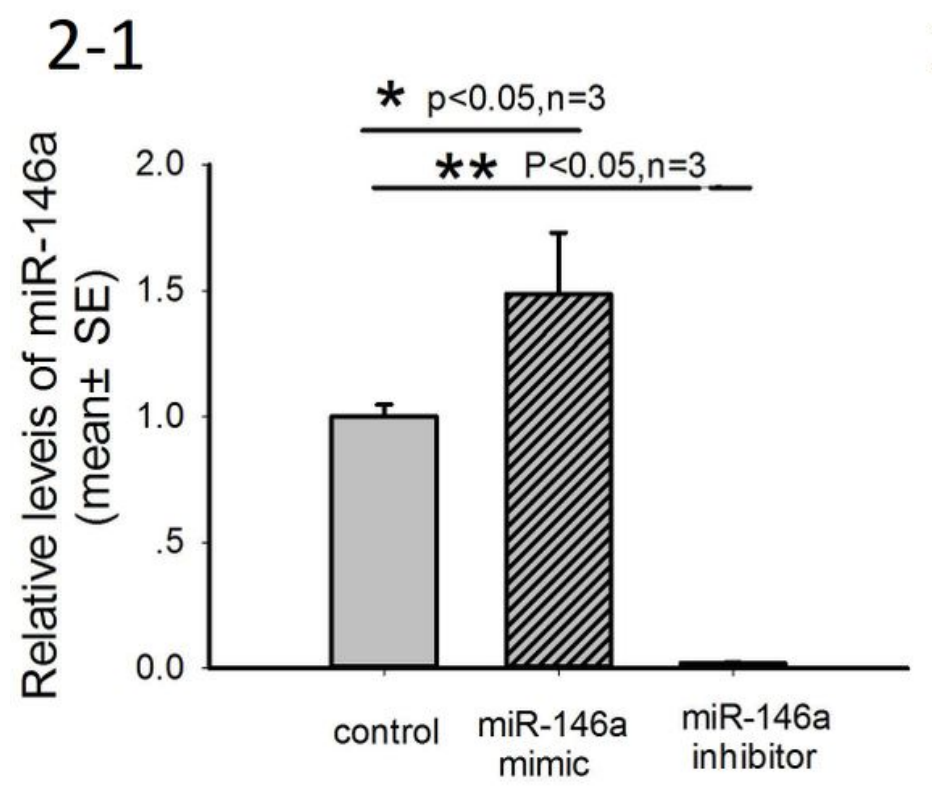

$2-2$

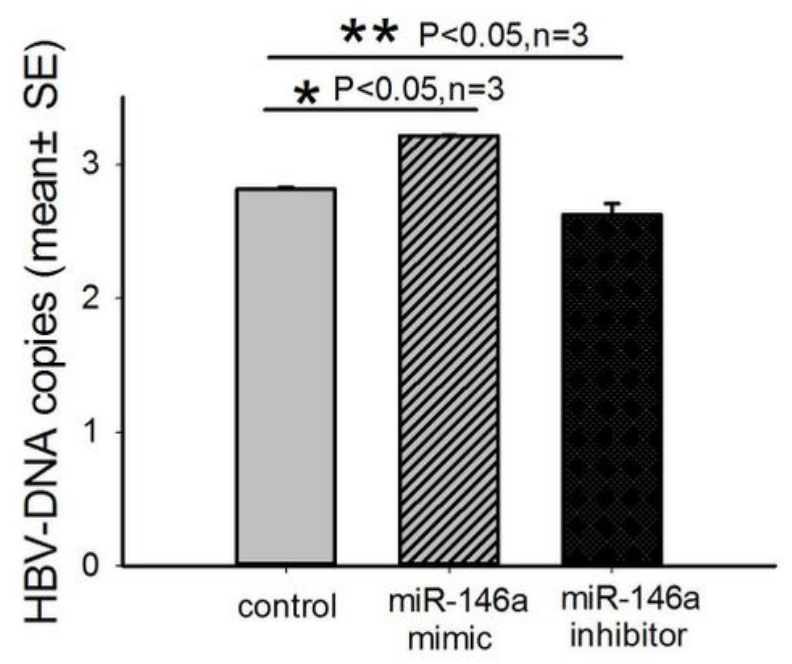

Figure 3

2-1 The level of miR-146a in HepG2.2.15 after transfection miR-146a. 2-2 The copies number of HBV-DNA in HepG2.2.15 after transfection miR-146a 
3-1

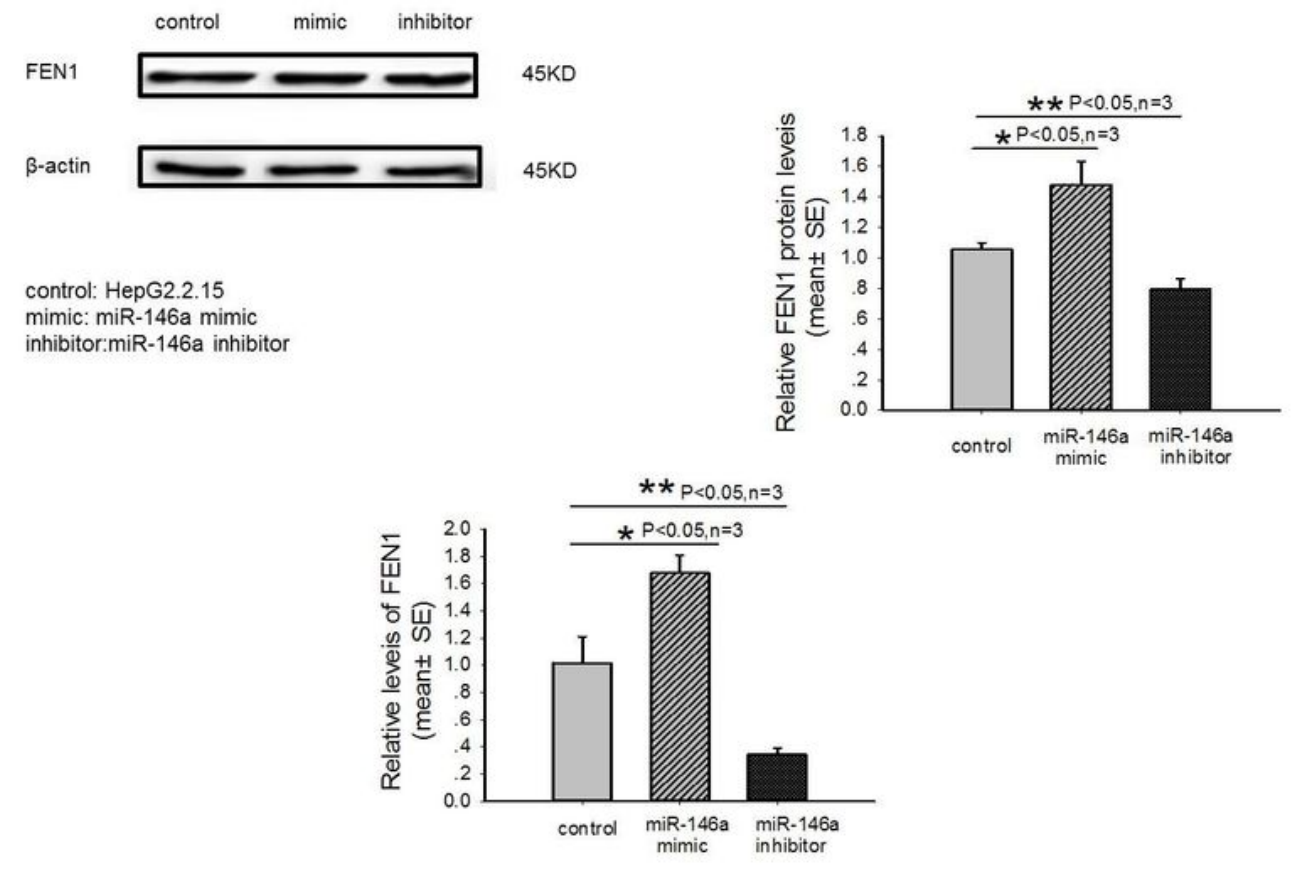

3-2
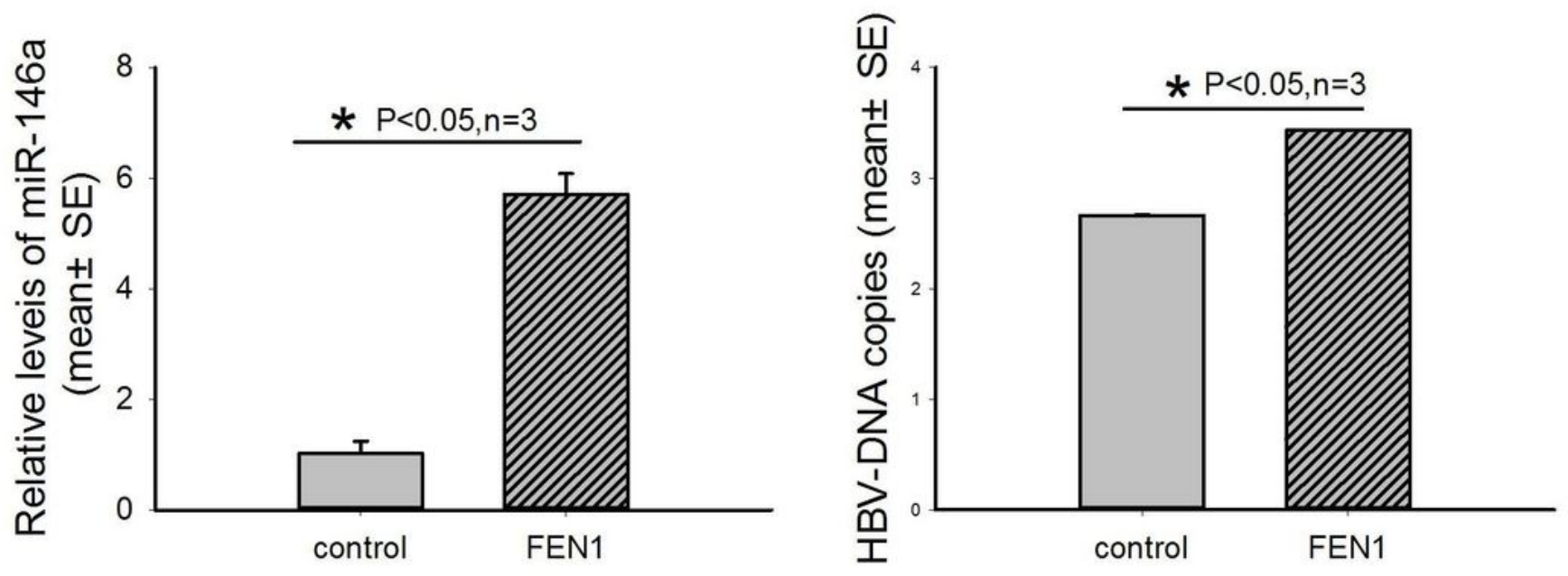

Figure 5

3-1 The expression of FEN1 in HepG2.2.15 cells after transfection miR-146a by qPCR and western blot. 32 The level of miR-146a and HBV DNA copies in HepG2.2.15 cells afrer transfection FEN1 

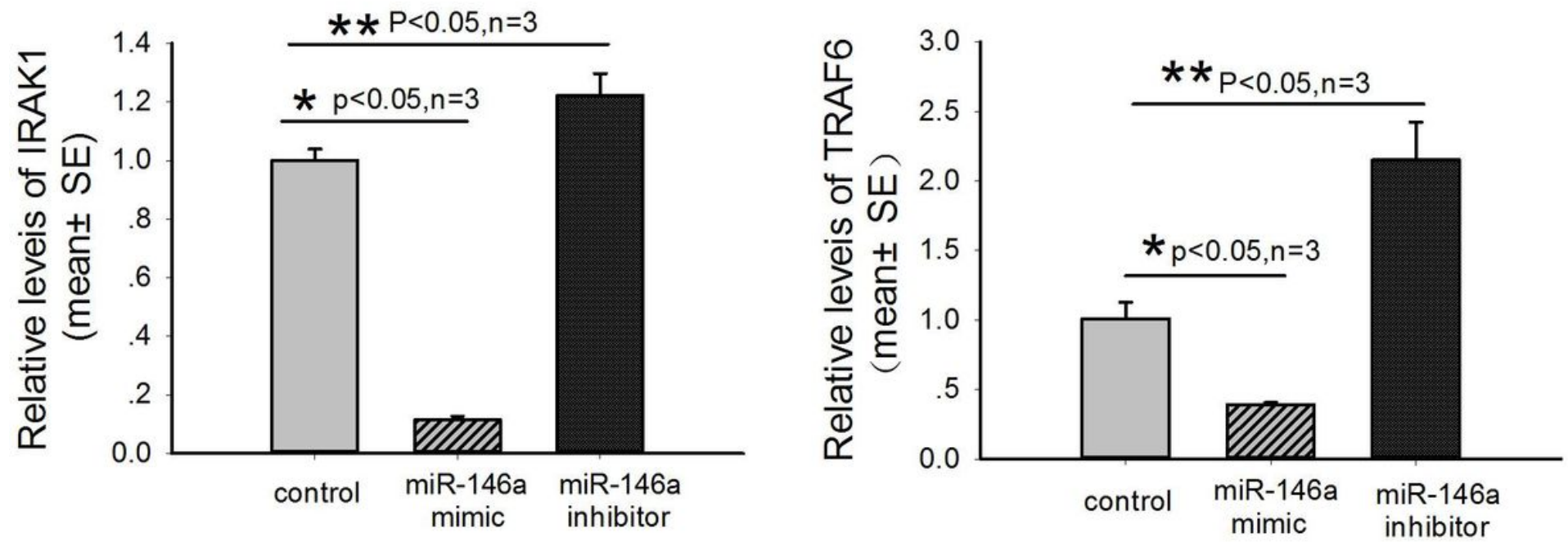

Figure 8

The expression of IRAK1/TRAF6 in HepG2.2.15 cells after transfection miR-146a 
5-1

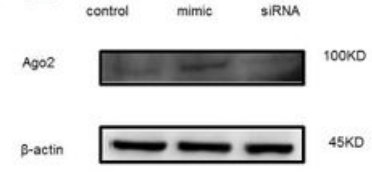

control: Hep Q2.2.15 mimic: miR-146a mimic
siRNA: Ago2 siRNA
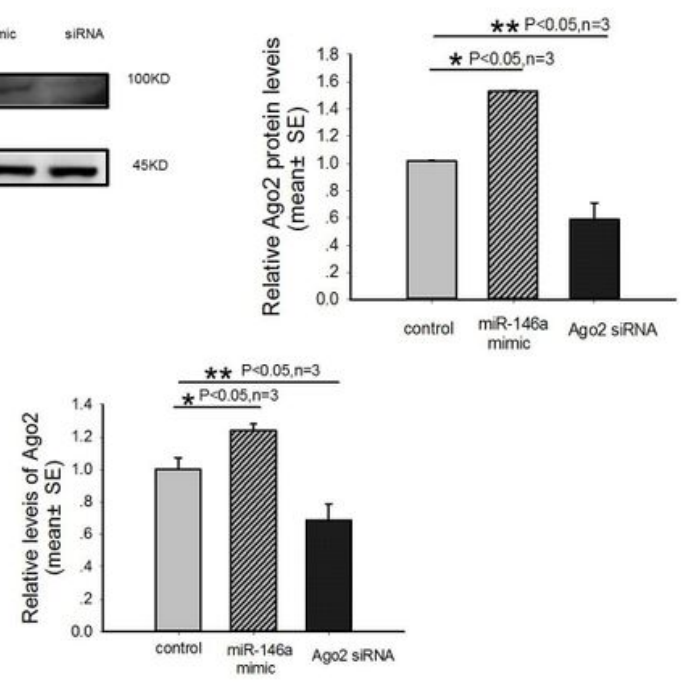

5-3

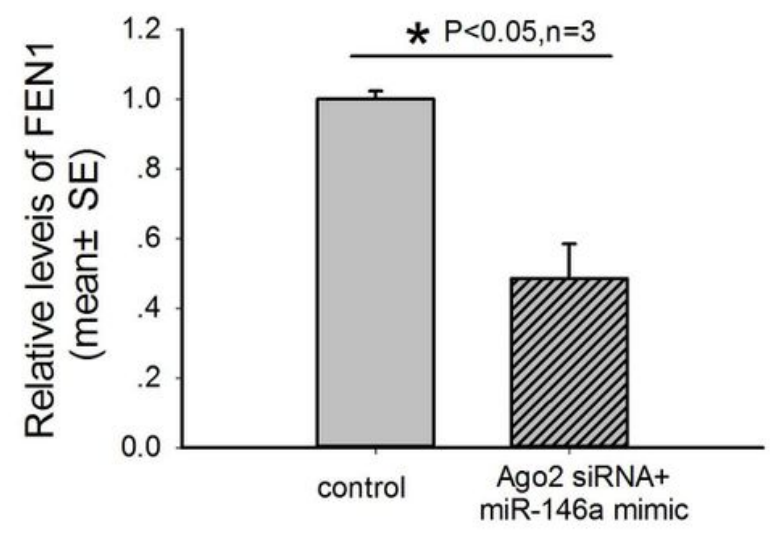

5-2

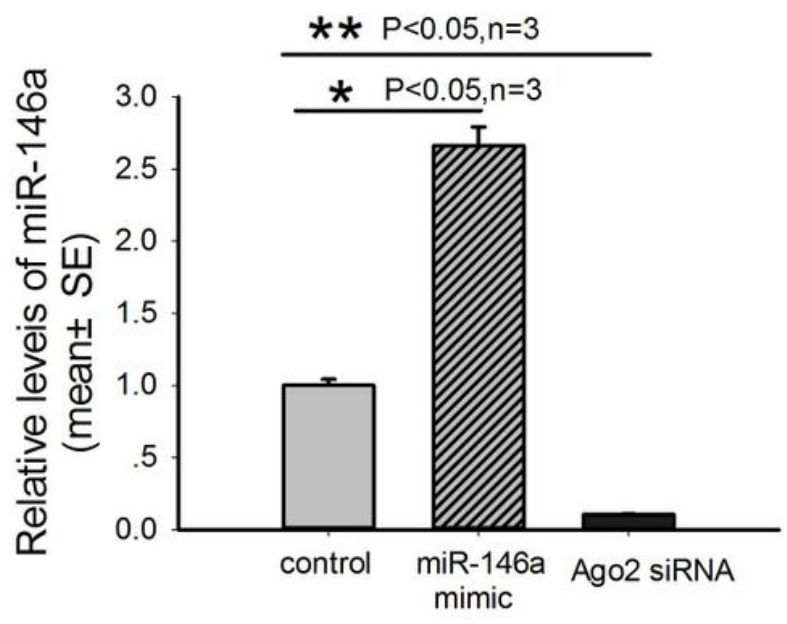

5-4

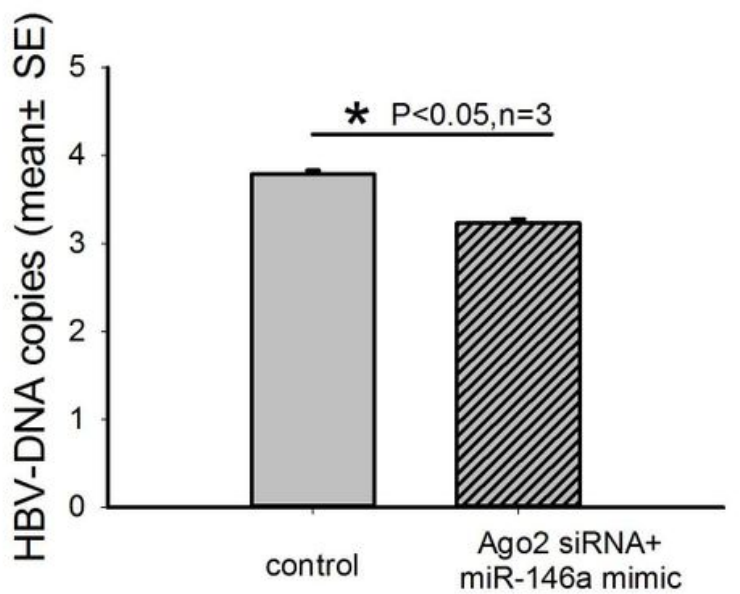

Figure 10

5-1 The expression of Ago2 in HepG2.2.15 cells after transfection miR-146a and Ago2 siRNA. The level of miR-146a after transfection miR-146a mimic and Ago2 siRNA into HepG2.2.15 cells. 5-3 The expression of FEN1 after transfection Ago2 siRNA and miR-146a into HepG2.2.15. 5-4 The copies of HBV DNA after transfection Ago2 siRNA and miR-146a into HepG2.2.15

\section{Supplementary Files}

This is a list of supplementary files associated with this preprint. Click to download.

- discussion.jpg

- discussion.jpg 